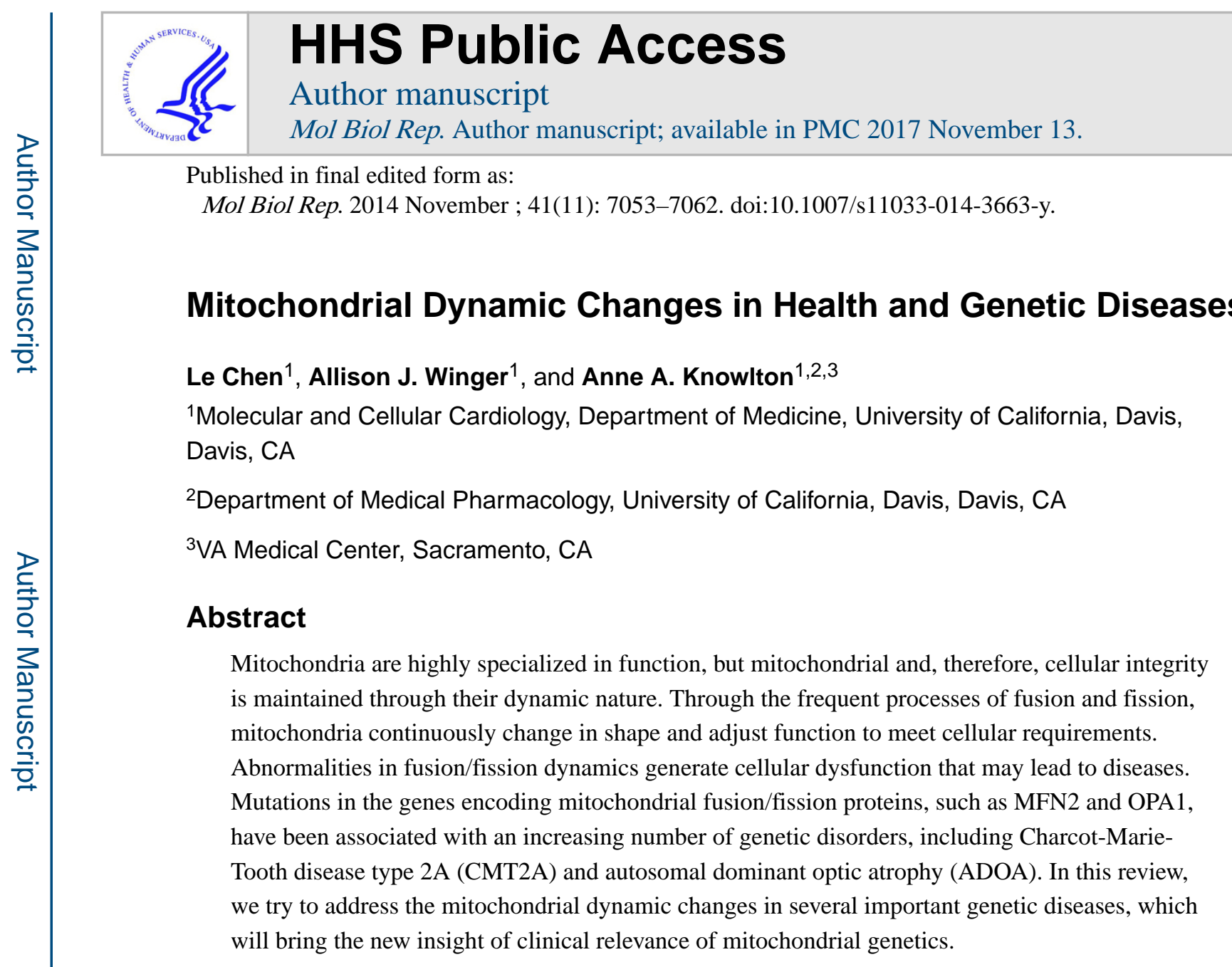

\title{
Mitochondrial Fusion and Fission
}

Mitochondrial fusion and fission are fundamental biological processes that influence cell function and survival. At steady state, overall mitochondrial morphology and function is maintained through balanced rates of fusion and fission events $(1,2)$. Regulating fusion/ fission may be involved in the inter-mitochondrial exchange of content and information, as well as promoting survival or eliminating damaged mitochondria (3-5). Mitochondrial fission facilitates mitochondrial distribution during cell division to achieve equal segregation into daughter cells and may help to segregate damaged sections of mitochondria and, thus, facilitate mitophagy (6). Fusion protects function by enabling mitochondria to combine their contents for protein complementation and mtDNA repair. Because the roles of mitochondrial fusion and fission are essential to cellular function, abnormalities such as loss of balanced fusion/fission rate can lead to apoptosis $(5,7)$. Among the proteins that control mitochondrial fission in mammalian cells are Drp1 (DNM1 in yeast) (8), as well as its receptors Fis1 (9) and Mff (10). Drp1, a large GTPase, exists in the cytoplasm and can form complexes that associate at organelle fission sites on the outer mitochondrial surface (11). When GTPase activity is inhibited with a dominant negative protein defective in GTP

Address for Correspondence: Le Chen, Ph.D., Molecular \& Cellular Cardiology, University of California, Davis, One Shields Avenue, Davis, CA 95616, lechen@ ucdavis.edu. A.A. Knowlton, M.D., Molecular \& Cellular Cardiology, University of California, Davis, One Shields Avenue, Davis, CA 95616, Tel. - 530-752-5461, Fax - 530-754-7167, aaknowlton@ucdavis.edu.

Conflict of Interest: None declared. 
binding, elongated mitochondria develop in mammalian cells (12). Human Fis1 (hFis1) localizes to the outer surface of mitochondria, but not specifically to mitochondrial fission sites (13). Use of RNA interference (RNAi) to down-regulate mammalian Fis1 expression also induces mitochondrial elongation (14). Independently to Fis1, mitochondrial fission factor (Mff) knockdown released the Drp1 foci from the mitochondrial outer membrane accompanied by mitochondrial elongation, whereas Mff overexpression stimulated mitochondrial recruitment of Drp1 accompanied by mitochondrial fission (10). Mitochondrial fusion in mammalian cells is controlled by the large GTPases mitofusin (MFN) 1, MFN2, and OPA 1 (MGM1 in yeast) (15-17). Loss of any of these proteins leads to mitochondrial fragmentation (17-20). Although debate persists, there is some data supporting that another mitochondrial membrane located protein, OPA3, also contributes to the mitochondrial fusion/fission process (21). Recent evidence showed that downregulation of OPA3 led to mitochondrial elongation (22), while overexpressing OPA3 contributed to mitochondrial fragmentation (23).

Mitochondrial cycling and culling is crucial to maintaining cellular homeostasis and is conducted through mitochondrial fusion, fission, and mitophagy. The renewal and distribution of proteins, respiratory chain components, and mtDNA ensures the maintenance and production of healthy mitochondria in the cell (24). Fragmented mitochondria are often targeted to mitophagy while mitochondrial fission is thought to precede mitophagy, but it is not sufficient for mitophagy initiation. OPA1 overexpression and DRP1 silencing causes excessive fusion and decreases mitophagy (25). Furthermore, MFN2 knockdown inhibits mitophagy by reducing lipid transfer between mitochondria and autophagosomes (26).

\section{Mitochondrial dynamic changes and human genetic diseases}

Mitochondrial dysfunction has been found in numerous genetic diseases. Initially, mitochondrial dynamic changes were associated with a few rare inherited neurodegenerative disorders such as CMT2A and ADOA (1). However, expanding evidence suggests that mitochondrial dynamic dysfunction is involved in some common diseases as well, including Parkinson's disease and diabetes, affecting almost all organs.

\section{Charcot-Marie-Tooth (CMT) Disease Type 2A (CMT2A)}

CMT disease is the most common congenital neuromuscular disorder with a prevalence of 1/2500. CMT affects motor and sensory neurons (27). The three main forms of axonal CMTs have been categorized by genetic studies as dominant (CMT2), recessive (CMT4C or AR-CMT2) and X-linked recessive (CMTX). Among patients with axonal dominant forms (CMT2), up to $20 \%$ have subtype CMT2A, which is specifically caused by mutations in MFN2 (27). To date, about 60 mutations on the MFN2 gene have been reported in CMT2A patients, almost all of which are single point mutations in MFN2coding regions leading to an amino acid substitution (27). Some of the clinical symptoms encountered by patients with CMT2A such as severe muscle atrophy are due to the expression of an MFN2 mutation (MFN2T105M), which causes severe abnormalities leading to massive motor axon degeneration (28). Remarkably, overexpression of MFN1 is capable of rescuing the defective mitochondrial fusion from MFN2 mutations because MFN1 and MFN2 wild-type physically 
associate while the CMT2A mutant promotes mitochondrial fusion (1). MFN2 mutations have also been detected in a hereditary motor and sensory neuropathy type VI case with optic atrophy (29).

\section{Autosomal dominant optic atrophy (ADOA)}

ADOA type 1 is a neurological disease involving axons of the retinal ganglion cells (RGCs) that comprise the optic nerve. This leads to reduced visual acuity and possibility of blindness with an incidence ranging from 1/12000 to 1/500000. Approximately 60-70\% of ADOA cases are autosomal dominant mutations caused by OPA1 mutations that cause to Kjer's disease (30). About $50 \%$ of these OPA1 mutations are predicted to truncate the protein and induce haplo-insufficiency due to frame-shift and nonsense mutations, stop codons, splicing errors, or deletions/insertions. The remaining mutated OPA1 proteins are due to missense mutations, which cause heterozygous amino acid substitutions with about $30 \%$ of these mutations being close to the GTPase domain (30). Zanna and colleagues have shown that ADOA-1 patients have a reduced rate of complex I-driven ATP synthesis (31). This study revealed a potential link between OPA1 mutations and defects in the respiratory chain by using co-immunoprecipitation to identify interactions between OPA1, AIF and respiratory complexes I, II and III. However, it remains controversial as these changes were not confirmed by other studies of different mutations in AODA patients. Muscle biopsies of AODA patients demonstrated neurogenic atrophy as well as abnormal morphology and distribution of mitochondria; however, they were not correlated with altered bioenergetics or increased susceptibility to pro-apoptotic stimuli (32). The OPA1-driven mitochondrial fusion in RGCs of ADOA1 patients with the deletion of the GTPase effector domain (OPA1 $\Delta 58)$ cannot adequately oppose fission, thus they are rendered more sensitive to apoptotic stimuli and optic nerve eventually degenerates (18). The wide range of mutations associated with ADOA likely accounts for both the broad spectrum of disease severity and differences in basic studies of mitochondrial function and apoptosis.

OPA3 mutations also cause ADOA and Cataract (ADOAC) and Type III 3-methylglutaconic aciduria. Two dominant missense mutations in OPA3 were identified in exon 2 as the $\mathrm{c}$. $277 \mathrm{G}>\mathrm{A}$ transition and the $\mathrm{c} .313 \mathrm{C}>\mathrm{G}$ transversion (33). Fibroblasts from ADOAC patients exhibited heightened apoptotic sensitivity, but did not develop abnormalities of the respiratory chain, mitochondrial membrane potential, or morphology. Type III 3methylglutaconic aciduria or Costeff syndrome is caused by an autosomal recessive OPA3 mutation, and presents with early-onset bilateral optic atrophy, spasticity, extrapyramidal signs, as well as a cognitive deficit (34). Ryu et al. observed cells that overexpress OPA3 are more sensitive to apoptotic stimuli because increased OPA3 triggered mitochondrial fragmentation, leading to cell death via a FIS1/DRP1-independent pathway (23). Interestingly, others have found that the balance between mitochondrial fission and fusion becomes offset when OPA3 mutations in the hydrophobic region inhibit mitochondrial fragmentation and induces the overexpression of MFN1 (23). The function of OPA3 is not well understood, and more investigations are needed in this area. 


\section{Parkinson's disease (PD)}

$\mathrm{PD}$ is a relatively prevalent, progressive neurodegenerative disorder characterized by loss of the nigrostriatal dopaminergic neurons leading mainly to movement-related symptoms.

About $10 \%$ of PD cases are familial with a genetic basis. PD risk increases have been associated with genetic mutations in many proteins linked to the mitochondria, such as $a$ synuclein, DJ-1, parkin, PINK1, and LRRK2 (35). Moreover, risk of PD increases upon exposure to neurotoxins and other environmental factors including 1-methyl-4phenyl-1,2,3,6-tetrahydropyridine (MPTP) via its active metabolite 1-methyl-4phenylpyridinium ion (MPP+) (36). Emerging evidence suggests that the mitochondrial dysfunction is an essential component of PD pathogenesis and this is supported by genetic PD models precipitated by abnormal mitochondrial dynamics. This has been recently nicely reviewed by Yan et al. (37).

Autosomal dominant PD is triggered by point mutations in mitochondrial proteins, such as the A53T and E46K mutations in $a$-synuclein. Overexpressing human $a$-synuclein in mice resulted in the development of dysfunctional mitochondria and increased oxidative stress (38), whereas the overexpression of the A35T $a$-synuclein mutation in transgenic mice lead to abnormal $a$-synuclein accumulation in the mitochondria, which were markedly abnormal (39). Another study recently demonstrated that a probable role of $a$-synuclein is to block spontaneous membrane fusion, as $\boldsymbol{a}$-synuclein overexpression results in mitochondrial fragmentation, independent of the fission and fusion machinery (40). A second, more recent study confirmed that DRP1-independent fragmentation was induced by $a$-synuclein overexpression (41). In contrast, others showed in vivo mitochondrial fragmentation due to A53T $a$-synuclein overexpression, which was concurrent with a drastic change in expression of DRP1/MFN1/MFN2 in neurons of both mito-CFP and A53T $a$-synuclein expressing transgenic mice (42). More work is needed to fully understand the function(s) of $a$-synuclein.

Autosomal recessive juvenile Parkinsonism develops secondary to mutations in either parkin or PINK1. Parkin and PINK1 have been widely investigated for their essential role in mitophagy. PINK1, a serine/threonine protein kinase located on the cytoplasmic side of the outer mitochondrial membrane, phosphorylates cytoplasmic parkin and causes its translocation to the mitochondria (43). The PINK1/parkin pathway encourages mitochondrial fission and/or impedes fusion by its negative regulation of MFN1/2 and OPA1 function, and/or the pathway's positive regulation of DRP1, as seen in Drosophila (44). The ubiquitination of MFN1/2, but not OPA1 or Fis1, was reported to be promoted by the PINK1/parkin pathway within an hour of $\mathrm{H}_{2} \mathrm{O}_{2}$ treatment in PD patient-derived fibroblast cells (45). Additionally, it has recently been demonstrated that wild-type parkin interacts with and ubiquitinates Drp1, but parkin with a pathogenic mutation or its knocked down inhibits Drp1 ubiquitination and degradation, which leads to an increased Drp1 resulting in mitochondrial fragmentation (46). Yu et al. discovered a decrease in mitochondrial size in primary neurons with PINK1 and parkin over-expression, in contrast to elongated mitochondria when they were silenced. Furthermore, it has been demonstrated in both Drosophila and a mammalian system that parkin-mediated ubiquitination and subsequent MFN2 degradation likely underlie suppressed mitochondrial fusion (47). Overall, these 
studies strongly suggest that the PINK1/parkin pathway directly influences mitochondrial dynamics.

Autosomal recessive early onset Parkinsonism is caused by pathogenic mutations in DJ-1, a small $20 \mathrm{kDa}$ protein with a crucial role in the cellular response to oxidative stress (48-50). Interestingly, it has been reported that fragmented mitochondria were found in human fibroblasts from DJ-1 E64D PD patients and in lymphoblasts derived from DJ-1 L166P or DJ-1 deletion mutation PD patients $(51,52)$. Moreover, extensive mitochondrial fragmentation as well as ultrastructural defects in M17 neuronal cells and primary cortical neurons are caused by the overexpression of several pathogenic DJ-1 mutants (52). In contrast, the overexpression of wild-type DJ-1 in neurons resulted in significantly elongated mitochondria, giving them an enhanced resistance to $\mathrm{H}_{2} \mathrm{O}_{2}$ and $\mathrm{MPP}+(52)$. Mouse embryonic fibroblasts with DJ-1 knockout exhibit extensive mitochondrial fragmentation, which reduces mitochondrial connectivity, but overexpression of wild type human DJ-1, PINK1 or parkin restores mitochondrial dynamics (53). These studies confirmed the contribution of DJ-1 in regulating mitochondrial dynamics.

Mutations in the leucine-rich repeat kinase 2 (LRRK2), a large multi-domain protein kinase, are linked to autosomal dominant PD. LRRK2 co-localizes with mitochondria in order to directly interact with Drp1 for recruitment, which induces mitochondrial fragmentation and dysfunction, while its kinase activity may also increase cell vulnerability to stress. PDassociated LRRK2 mutants further aggravate these effects (54). After treatment with P110, a selective peptide inhibitor of Drp1, both LRRK2G2019S-expressing cells and PD patient fibroblasts carrying this specific mutant showed reduced mitochondrial fragmentation and damage (55). This suggests a possible new approach for treatment of PD through inhibition of Drp1-mediated increased mitochondrial fission.

In addition to the PD gene related mitochondrial disorder, other studies demonstrated that the neurotoxin, MPP+, induces a DRP1-dependent biphasic increase in mitochondrial fragmentation while simultaneously decreasing ATP levels in both SH-SY5Y neuroblastoma cells and primary rat dopaminergic midbrain neurons (46). Indeed, attenuation of mitochondrial fragmentation by DRP1 knockdown reduces the downstream events induced by MPP+, including ROS accumulation and ATP depletion.

\section{Alzheimer's diseases (AD)}

Familial AD (more than 2 persons in a family are affected) accounts for approximately $25 \%$ of all $\mathrm{AD}$ and, of those afflicted with familial $\mathrm{AD}, 95 \%$ is considered late onset (occurring after 65 years of age) and 5\% is early onset (56). AD neurons have fewer mitochondria with an increased size, suggesting a potential incidence of abnormal mitochondrial dynamics in the AD brain (57).

An increasing number of reports are showing that the dynamic nature of the mitochondria is disturbed in AD brain. Supporting studies that reveal significant changes in protein levels such as decreased MFN1/2 and OPA1 affecting mitochondrial fusion, and decreased DRP1 and increased Fis1 disrupting fission in the AD brain (58-60). Although the total cellular 
levels of DRP1 decrease, mitochondrial DRP1 used for mitochondrial fission as well as phosphorylated Ser616DRP1 (a posttranslational modification to facilitate mitochondrial translocation) are increased in $\mathrm{AD}$ brain (58).

S-nitrosylation of DRP1 facilitates mitochondrial fission by activating the GTPase activity of DRP1 and is also increased in AD brain (61). Furthermore, the interaction of Drp1 with amyloid beta $(\mathrm{A} \beta)$ lead to abnormal mitochondrial dynamics and damage to the synapse, resulting in $\mathrm{AD}$ disease progression (62). Interestingly, nitric oxide production enhanced by $A \beta$ was reported to trigger mitochondrial fission and cause neuronal damage because it activated Drp1 GTPase activity via C644 nitrosylation (63), although the proposed process was challenged (64). The combination of the decreased fusion proteins and increased Fis 1 in $\mathrm{AD}$ brain (62) in peripheral blood lymphocytes from $\mathrm{AD}(65)$ suggest that the increased mitochondrial fragmentation in AD likely contributes to mitochondrial dysfunction.

\section{Huntington's diseases (HD)}

$\mathrm{HD}$, the devastating autosomal dominant neurodegenerative disorder, is caused by the abnormal triplet expansion of the CAG repeat in exon 1 of the HD gene. This mutated gene generates an elongated polyglutamine stretch in the protein product called mutant Htt that may directly bind the mitochondria (3). Studies have demonstrated the localization of mutant $\mathrm{Htt}$ to the outer mitochondrial membrane using both HD transgenic mice and HD striatal cells (STHdhQ111) (66). The discovery of Htt aggregates localized to the mitochondria (67) suggests that mitochondrial dysfunction contributes to HD. Apoptotic stimulation in cellular models of HD reveals the aggravation of mitochondrial cristae alterations characteristic of fragmented HD mitochondria (68). Studies on cellular models of $\mathrm{HD}$ as well as HD postmortem brain tissue have reported an increased expression of Drp1 and Fis1, and depressed expression of mitofusins and OPA1 (69-72). The direct interaction between mutant Htt and Drp1 stimulates DRP1 GTPase activity, leading both in vivo and in vitro to mitochondrial fragmentation. Thus, the critical mitochondrial fusion/fission balance is impaired and neuronal cell death ensues (71). However, this issue is not resolved, as others have reported increased vacuolization, abnormal cristae, and giant mitochondria in the skin fibroblasts and muscle tissues from HD patients (73). In sum, although controversial, the evidence supports a role for impaired mitochondrial fusion/fission in HD.

\section{Diabetes}

Mitochondria have an important function in insulin secretion and mutation in mitochondrial DNA leads to the known etiological subdivision of diabetes (74). Pancreatic $\beta$-cells require healthy mitochondrial function in order to properly regulate insulin secretion. The pancreatic islets of patients with type 2 diabetes have mitochondria that are both functionally and morphologically altered with decreased mitochondrial membrane potential, depressed ATP production, and many swollen mitochondria (75). Mitochondria from $\beta$-cells in the Zucker diabetic fatty rat model were reported as short and swollen, and reduced levels of both MFN2 mRNA and protein were confirmed (76). Islet beta cells exposed to hyperglycemic conditions resulted in a drastic increase in Drp1 expression. When Drp1 expression was induced, Drp1 wild-type cells from inducible beta cell line significantly promoted high 
glucose-induced apoptosis, but this was not observed in the Drp1K38A (dominant negative Drp1 mutant) inducible beta cell line (77). The downregulation of Fis1 in $\beta$-cell mitochondria may significantly reduce high glucose-induced insulin secretion via decreased respiration (78). $\beta$-cells with overexpressed hFis1 or MFN1 contained smaller mitochondria and lower levels of cellular ATP, and therefore had impaired glucose-stimulated insulin secretion as well (79). Key proteins in mitochondrial dynamics such as OPA1, DRP1, and Fis1 were manipulated in order to test their role in $\beta$-cell mitochondrial morphology (80). In this case, increasing mitochondrial fusion proteins inhibited mitochondrial fragmentation, maintained mitochondrial dynamics, and blocked apoptosis. Mice $\beta$-cells lacking OPA1 develop hyperglycemia, which suggests that OPA1 is physiologically relevant in $\beta$-cells in order to maintain the electron transport chain (81). Mitochondria found in the skeletal muscle of both mice with genetic and diet-induced obesity were smaller and shorter with increased fission machinery. Mitochondrial fission inhibition led to improved muscle cell insulin signaling, as well as to better systemic insulin sensitivity in obese mice (82). Interestingly, after three hours of insulin treatment, OPA1 protein levels and mitochondrial membrane potential increased, mitochondrial fusion was improved, and both intracellular ATP levels and oxygen consumption in cardiomyocytes in vitro and in vivo were elevated (83). These observations suggest disruption of mitochondrial dynamics in diabetes may contribute to diabetic pathologies at a cellular and organ level.

\section{Cardiomyopathy}

In patients, especially children, with mitochondrial disease, cardiomyopathy was common (17\% of patients) and was associated with increased mortality (84). However, studies are limited as to whether inherited cardiomyopathy is associated with changes in mitochondrial dynamics. In part this reflects the diversity of inherited cardiomyopathy. In vivo investigations suggest some degree of impaired cardiac function that ranges from moderate hypertrophy observed in MFN2 knockout mice to severe heart failure in the absence of both mitofusins $(85,86)$. An OPA1 aberrant expression mouse, modeling ADOA, has also been associated with late-onset cardiomyopathy in mouse models with a heterozygous null OPA1 mutation (87). The heterozygous mutation of OPA3 in exon 2, modeling ADOAC, lead to a dilated cardiomyopathy (88). These evidences suggested an important potential role for abnormalities of mitochondrial dynamics in inherited cardiomyopathy.

\section{Mechanisms in Mitochondrial Dynamic Related Diseases}

Mitochondrial fusion/fission plays critical roles in maintaining mitochondrial morphology, and has been strongly linked to mtDNA stability, antioxidant processes and apoptosis. In almost all the genetic diseases discussed above, loss of balanced mitochondrial dynamics may contribute to the phenotypes/syndromes.

\section{mtDNA Loss and Mitochondrial Dynamics}

Many mitochondrial disorders are accompanied by mtDNA mutation or deletion. Mitochondrial dynamic proteins have been linked to maintenance of the stability of mtDNA. The "ADOA plus" syndromes are associated with a subset of OPA1 missense mutations 
(89). This syndrome usually involves not only vision loss, but also weakness in the muscles (ophthalmoplegia, ataxia), hearing loss, motor and sensory neuropathy, and muscle weakness (myopathy). A subset of OPA1 missense mutations have been correlated with the "ADOA plus" syndrome, as well as with stable tissues like skeletal muscle that have accumulated mtDNA deletions (89). The implication of MFN2 in mtDNA maintenance, replication, and repair is indirectly supported by the qualitative (multiple deletions) and quantitative (depletion) abnormalities of mtDNA in the skeletal muscle of mitofusindeficient mice (90). OPA1 heterozygous mutation also caused significant mtDNA loss in a mouse modeling ADOA (87). High levels of mtDNA deletions in CMT2A patients have been confirmed, which suggests that MFN2 mutations affect mtDNA replication by altering mitochondrial oxidative phosphorylation (91). mtDNA is also affected by PD, while greater levels of mtDNA damage was detected in neural cells from patients carrying homozygous or heterozygous LRRK2 G2019S mutations (92). mtDNA deletions, as well as other alterations, can result from oxidative damage to nucleic acids in AD patients (93). In a clinic study with AD patients, markedly increased level of mtDNA deletions has been found (94).

\section{Oxidative stress and Mitochondrial Dynamics}

Mitochondrial fusion/fission balance is particularly susceptible to oxidative stress. For example, it has been shown that hydrogen peroxide at low levels elicits reversible mitochondrial swelling, fragmentation, and fine structural alterations by modulation of fission/fusion proteins (95). Mitochondrial depolarization, such as from a sustained cytosolic $\mathrm{Ca} 2+$ influx, triggers significant mitochondrial fragmentation, presumably secondary to phosphorylation of DRP1 (96). On the other hand, excessive mitochondrial fragmentation can enhance ROS production. For example, high-glucose-induced respiration escalation and ROS overproduction are secondary to mitochondrial fragmentation facilitated by excessive fission (97). Decreased antioxidant gene expression, reduced total antioxidant capacity, as well as accumulated ROS, has been found in the OPA1 mutant mouse heart (87). Defects in mitochondrial dynamics may cause damaged mitochondrial components to accumulate due to inefficient elimination through mitophagy coupled with fission (25). A direct adverse effect on the function of critical mitochondrial protein complexes is also implicated because mitochondrial fission may also be necessary for the proper assembly and function of mitochondrial ETC complexes (87). Thus, the balance of mitochondrial fission/fusion can be offset by oxidative stress, which would further amplify ROS generation.

\section{Apoptosis and Mitochondrial Dynamics}

It has been generally accepted that loss of balanced mitochondrial fusion/fission, especially in a favor of fission, results in apoptosis. Manipulating mitochondrial fusion or fission proteins has been widely used to investigate the relationship between mitochondrial dynamic changes and apoptosis $(19,20,98-101)$. The well-known apoptotic pathways, including $\mathrm{Bcl} 2$, Bax, Bnip3 and Endogenous G, have all been reported to be involved in the mitochondrial dynamic related apoptosis (101-104). However, this still remains controversial. In some MFN1/2 or OPA1 mutation cases, especially in CMT2A and ADOA patients and genetic animal models, changes in apoptosis are not obvious $(86,105-108)$. 


\section{Summary}

Mitochondria dynamic equilibrium plays a vital role in maintaining health through their regulation of mitochondrial function. Unbalanced mitochondrial fusion/fission has been identified in many mitochondria related genetic diseases, in which mtDNA deletion, apoptosis, and ROS accumulation lead to marked dysfunction. The growing investigation of the mitochondrial dynamic pathways will provide the new insights into therapeutic approaches to these genetic diseases.

\section{Acknowledgments}

This work was supported by the National Institutes of Health [grant numbers HL077281, HL079071] and a Merit Award from the Department of Veterans Affairs (all to AAK).

\section{References}

1. Chen H, Chan DC. Physiological functions of mitochondrial fusion. Ann N Y Acad Sci. 2010; 1201:21-25. [PubMed: 20649534]

2. Knowlton AA, Chen L, Malik ZA. Heart Failure and Mitochondrial Dysfunction: The Role of Mitochondrial Fission/Fusion Abnormalities and New Therapeutic Strategies. J Cardiovasc Pharmacol. 2013

3. Chaturvedi RK, Flint Beal M. Mitochondrial Diseases of the Brain. Free Radical Biology and Medicine. 2013; 63:1-29. [PubMed: 23567191]

4. Graef M, Nunnari J. A role for mitochondria in autophagy regulation. Autophagy. 2011:7.

5. Westermann B. Mitochondrial fusion and fission in cell life and death. Nat Rev Mol Cell Biol. 2010; 11:872-884. [PubMed: 21102612]

6. Twig G, Elorza A, Molina AJA, Mohamed H, Wikstrom JD, Walzer G, Stiles L, Haigh SE, Katz S, Las G, Alroy J, Wu M, Py BF, Yuan J, Deeney JT, Corkey BE, Shirihai OS. Fission and selective fusion govern mitochondrial segregation and elimination by autophagy. EMBO J. 2008; 27:433446. [PubMed: 18200046]

7. Sheridan C, Martin SJ. Mitochondrial fission/fusion dynamics and apoptosis. Mitochondrion. 2010; 10:640-648. [PubMed: 20727425]

8. Bleazard W, McCaffery JM, King EJ, Bale S, Mozdy A, Tieu Q, Nunnari J, Shaw JM. The dynaminrelated GTPase Dnm1 regulates mitochondrial fission in yeast. Nat Cell Biol. 1999; 1:298-304. [PubMed: 10559943]

9. Yoon Y, Krueger EW, Oswald BJ, McNiven MA. The mitochondrial protein hFis1 regulates mitochondrial fission in mammalian cells through an interaction with the dynamin-like protein DLP1. Mol Cell Biol. 2003; 23:5409-5420. [PubMed: 12861026]

10. Otera H, Wang C, Cleland MM, Setoguchi K, Yokota S, Youle RJ, Mihara K. Mff is an essential factor for mitochondrial recruitment of Drp1 during mitochondrial fission in mammalian cells. J Cell Biol. 2010; 191:1141-1158. [PubMed: 21149567]

11. Smirnova E, Griparic L, Shurland DL, van der Bliek AM. Dynamin-related protein Drp1 is required for mitochondrial division in mammalian cells. Mol Biol Cell. 2001; 12:2245-2256. [PubMed: 11514614]

12. Estaquier J, Arnoult D. Inhibiting Drp1-mediated mitochondrial fission selectively prevents the release of cytochrome c during apoptosis. Cell Death Differ. 2007; 14:1086-1094. [PubMed: 17332775]

13. Suzuki M, Jeong SY, Karbowski M, Youle RJ, Tjandra N. The solution structure of human mitochondria fission protein Fis1 reveals a novel TPR-like helix bundle. J Mol Biol. 2003; 334:445-458. [PubMed: 14623186]

14. Stojanovski D, Koutsopoulos OS, Okamoto K, Ryan MT. Levels of human Fis1 at the mitochondrial outer membrane regulate mitochondrial morphology. J Cell Sci. 2004; 117:12011210. [PubMed: 14996942] 
15. Ishihara N, Fujita Y, Oka T, Mihara K. Regulation of mitochondrial morphology through proteolytic cleavage of OPA1. EMBO J. 2006; 25:2966-2977. [PubMed: 16778770]

16. Chen H, Detmer SA, Ewald AJ, Griffin EE, Fraser SE, Chan DC. Mitofusins Mfn1 and Mfn2 coordinately regulate mitochondrial fusion and are essential for embryonic development. J Cell Biol. 2003; 160:189-200. [PubMed: 12527753]

17. Huang P, Yu T, Yoon Y. Mitochondrial clustering induced by overexpression of the mitochondrial fusion protein Mfn2 causes mitochondrial dysfunction and cell death. Eur J Cell Biol. 2007; 86:289-302. [PubMed: 17532093]

18. Olichon A, Landes T, Arnauné-Pelloquin L, Emorine LJ, Mils V, Guichet A, Delettre C, Hamel C, Amati-Bonneau P, Bonneau D, Reynier P, Lenaers G, Belenguer P. Effects of OPA1 mutations on mitochondrial morphology and apoptosis: Relevance to ADOA pathogenesis. Journal of Cellular Physiology. 2007; 211:423-430. [PubMed: 17167772]

19. Olichon A, Baricault L, Gas N, Guillou E, Valette A, Belenguer P, Lenaers G. Loss of OPA1 perturbates the mitochondrial inner membrane structure and integrity, leading to cytochrome $\mathrm{c}$ release and apoptosis. J Biol Chem. 2003; 278:7743-7746. [PubMed: 12509422]

20. Lee Y, Jeong S, Karbowski M, Smith C, Youle R. Roles of the mammalian mitochondrial fission and fusion mediators Fis1, Drp1, and Opa1 in apoptosis. Mol Biol Cell. 2004; 15:5001-5011. [PubMed: 15356267]

21. Grau T, Burbulla LF, Engl G, Delettre C, Delprat B, Oexle K, Leo-Kottler B, Roscioli T, Kruger R, Rapaport D, Wissinger B, Schimpf-Linzenbold S. A novel heterozygous OPA3 mutation located in the mitochondrial target sequence results in altered steady-state levels and fragmented mitochondrial network. J Med Genet. 2013; 50:848-858. [PubMed: 24136862]

22. Ryu SW, Yoon J, Yim N, Choi K, Choi C. Downregulation of OPA3 is responsible for transforming growth factor-beta-induced mitochondrial elongation and F-actin rearrangement in retinal pigment epithelial ARPE-19 cells. PLoS One. 2013; 8:e63495. [PubMed: 23658835]

23. Ryu SW, Jeong HJ, Choi M, Karbowski M, Choi C. Optic atrophy 3 as a protein of the mitochondrial outer membrane induces mitochondrial fragmentation. Cell Mol Life Sci. 2010; 67:2839-2850. [PubMed: 20372962]

24. Scorrano L. Keeping mitochondria in shape: a matter of life and death. Eur J Clin Invest. 2013; 43:886-893. [PubMed: 23869410]

25. Twig G, Hyde B, Shirihai OS. Mitochondrial fusion, fission and autophagy as a quality control axis: the bioenergetic view. Biochim Biophys Acta. 2008; 1777:1092-1097. [PubMed: 18519024]

26. Hailey DW, Rambold AS, Satpute-Krishnan P, Mitra K, Sougrat R, Kim PK, Lippincott-Schwartz J. Mitochondria supply membranes for autophagosome biogenesis during starvation. Cell. 2010; 141:656-667. [PubMed: 20478256]

27. Cartoni R, Martinou JC. Role of mitofusin 2 mutations in the physiopathology of Charcot-MarieTooth disease type 2A. Exp Neurol. 2009; 218:268-273. [PubMed: 19427854]

28. Detmer SA, Vande Velde C, Cleveland DW, Chan DC. Hindlimb gait defects due to motor axon loss and reduced distal muscles in a transgenic mouse model of Charcot-Marie-Tooth type 2A. Hum Mol Genet. 2008; 17:367-375. [PubMed: 17959936]

29. Voo I, Allf BE, Udar N, Silva-Garcia R, Vance J, Small KW. Hereditary motor and sensory neuropathy type VI with optic atrophy. American journal of ophthalmology. 2003; 136:670-677. [PubMed: 14516807]

30. Votruba M, Aijaz S, Moore AT. A review of primary hereditary optic neuropathies. J Inherit Metab Dis. 2003; 26:209-227. [PubMed: 12889662]

31. Zanna C, Ghelli A, Porcelli AM, Karbowski M, Youle RJ, Schimpf S, Wissinger B, Pinti M, Cossarizza A, Vidoni S, Valentino ML, Rugolo M, Carelli V. OPA1 mutations associated with dominant optic atrophy impair oxidative phosphorylation and mitochondrial fusion. Brain. 2008; 131:352-367. [PubMed: 18222991]

32. Spinazzi M, Cazzola S, Bortolozzi M, Baracca A, Loro E, Casarin A, Solaini G, Sgarbi G, Casalena G, Cenacchi G, Malena A, Frezza C, Carrara F, Angelini C, Scorrano L, Salviati L, Vergani L. A novel deletion in the GTPase domain of OPA1 causes defects in mitochondrial morphology and distribution, but not in function. Hum Mol Genet. 2008; 17:3291-3302.

[PubMed: 18678599] 
33. Ayrignac X, Liauzun C, Lenaers G, Renard D, Amati-Bonneau P, de Seze J, Dollfus H, Hamel C, Bonneau D, Labauge P. OPA3--related autosomal dominant optic atrophy and cataract with ataxia and areflexia. European neurology. 2012; 68:108-110. [PubMed: 22797356]

34. Neas K, Bennetts B, Carpenter K, White R, Kirk EP, Wilson M, Kelley R, Baric I, Christodoulou J. OPA3 mutation screening in patients with unexplained 3-methylglutaconic aciduria. J Inherit Metab Dis. 2005; 28:525-532. [PubMed: 15902555]

35. Henchcliffe C, Beal MF. Mitochondrial biology and oxidative stress in Parkinson disease pathogenesis. Nature clinical practice Neurology. 2008; 4:600-609.

36. Lesage S, Brice A. Parkinson's disease: from monogenic forms to genetic susceptibility factors. Hum Mol Genet. 2009; 18:R48-59. [PubMed: 19297401]

37. Yan MH, Wang X, Zhu X. Mitochondrial defects and oxidative stress in Alzheimer disease and Parkinson disease. Free Radic Biol Med. 2013; 62:90-101. [PubMed: 23200807]

38. Song DD, Shults CW, Sisk A, Rockenstein E, Masliah E. Enhanced substantia nigra mitochondrial pathology in human alpha-synuclein transgenic mice after treatment with MPTP. Exp Neurol. 2004; 186:158-172. [PubMed: 15026254]

39. Martin LJ, Pan Y, Price AC, Sterling W, Copeland NG, Jenkins NA, Price DL, Lee MK. Parkinson's disease alpha-synuclein transgenic mice develop neuronal mitochondrial degeneration and cell death. J Neurosci. 2006; 26:41-50. [PubMed: 16399671]

40. Kamp F, Exner N, Lutz AK, Wender N, Hegermann J, Brunner B, Nuscher B, Bartels T, Giese A, Beyer K, Eimer S, Winklhofer KF, Haass C. Inhibition of mitochondrial fusion by alpha-synuclein is rescued by PINK1, Parkin and DJ-1. Embo j. 2010; 29:3571-3589. [PubMed: 20842103]

41. Nakamura K, Nemani VM, Azarbal F, Skibinski G, Levy JM, Egami K, Munishkina L, Zhang J, Gardner B, Wakabayashi J, Sesaki H, Cheng Y, Finkbeiner S, Nussbaum RL, Masliah E, Edwards RH. Direct membrane association drives mitochondrial fission by the Parkinson disease-associated protein alpha-synuclein. J Biol Chem. 2011; 286:20710-20726. [PubMed: 21489994]

42. Xie W, Chung KK. Alpha-synuclein impairs normal dynamics of mitochondria in cell and animal models of Parkinson's disease. J Neurochem. 2012; 122:404-414. [PubMed: 22537068]

43. Kim Y, Park J, Kim S, Song S, Kwon SK, Lee SH, Kitada T, Kim JM, Chung J. PINK1 controls mitochondrial localization of Parkin through direct phosphorylation. Biochem Biophys Res Commun. 2008; 377:975-980. [PubMed: 18957282]

44. Deng H, Dodson MW, Huang H, Guo M. The Parkinson's disease genes pink1 and parkin promote mitochondrial fission and/or inhibit fusion in Drosophila. Proc Natl Acad Sci U S A. 2008; 105:14503-14508. [PubMed: 18799731]

45. Rakovic A, Grunewald A, Kottwitz J, Bruggemann N, Pramstaller PP, Lohmann K, Klein C. Mutations in PINK1 and Parkin impair ubiquitination of Mitofusins in human fibroblasts. PLoS One. 2011; 6:e16746. [PubMed: 21408142]

46. Wang X, Su B, Liu W, He X, Gao Y, Castellani RJ, Perry G, Smith MA, Zhu X. DLP1-dependent mitochondrial fragmentation mediates 1-methyl-4-phenylpyridinium toxicity in neurons: implications for Parkinson's disease. Aging Cell. 2011; 10:807-823. [PubMed: 21615675]

47. Yang Y, Ouyang Y, Yang L, Beal MF, McQuibban A, Vogel H, Lu B. Pink1 regulates mitochondrial dynamics through interaction with the fission/fusion machinery. Proc Natl Acad Sci U S A. 2008; 105:7070-7075. [PubMed: 18443288]

48. Bonifati V, Rizzu P, van Baren MJ, Schaap O, Breedveld GJ, Krieger E, Dekker MC, Squitieri F, Ibanez P, Joosse M, van Dongen JW, Vanacore N, van Swieten JC, Brice A, Meco G, van Duijn CM, Oostra BA, Heutink P. Mutations in the DJ-1 gene associated with autosomal recessive earlyonset parkinsonism. Science. 2003; 299:256-259. [PubMed: 12446870]

49. Taira T, Saito Y, Niki T, Iguchi-Ariga SM, Takahashi K, Ariga H. DJ-1 has a role in antioxidative stress to prevent cell death. EMBO Rep. 2004; 5:213-218. [PubMed: 14749723]

50. Clements CM, McNally RS, Conti BJ, Mak TW, Ting JP. DJ-1, a cancer- and Parkinson's diseaseassociated protein, stabilizes the antioxidant transcriptional master regulator Nrf2. Proc Natl Acad Sci U S A. 2006; 103:15091-15096. [PubMed: 17015834]

51. Irrcher I, Aleyasin H, Seifert EL, Hewitt SJ, Chhabra S, Phillips M, Lutz AK, Rousseaux MW, Bevilacqua L, Jahani-Asl A, Callaghan S, MacLaurin JG, Winklhofer KF, Rizzu P, Rippstein P, Kim RH, Chen CX, Fon EA, Slack RS, Harper ME, McBride HM, Mak TW, Park DS. Loss of the 
Parkinson's disease-linked gene DJ-1 perturbs mitochondrial dynamics. Hum Mol Genet. 2010; 19:3734-3746. [PubMed: 20639397]

52. Krebiehl G, Ruckerbauer S, Burbulla LF, Kieper N, Maurer B, Waak J, Wolburg H, Gizatullina Z, Gellerich FN, Woitalla D, Riess O, Kahle PJ, Proikas-Cezanne T, Kruger R. Reduced basal autophagy and impaired mitochondrial dynamics due to loss of Parkinson's disease-associated protein DJ-1. PLoS One. 2010; 5:e9367. [PubMed: 20186336]

53. Blackinton J, Lakshminarasimhan M, Thomas KJ, Ahmad R, Greggio E, Raza AS, Cookson MR, Wilson MA. Formation of a stabilized cysteine sulfinic acid is critical for the mitochondrial function of the parkinsonism protein DJ-1. J Biol Chem. 2009; 284:6476-6485. [PubMed: 19124468]

54. Wang X, Yan MH, Fujioka H, Liu J, Wilson-Delfosse A, Chen SG, Perry G, Casadesus G, Zhu X. LRRK2 regulates mitochondrial dynamics and function through direct interaction with DLP1. Hum Mol Genet. 2012; 21:1931-1944. [PubMed: 22228096]

55. Su YC, Qi X. Inhibition of excessive mitochondrial fission reduced aberrant autophagy and neuronal damage caused by LRRK2 G2019S mutation. Hum Mol Genet. 2013; 22:4545-4561. [PubMed: 23813973]

56. Roses AD, Saunders AM. Perspective on a pathogenesis and treatment of Alzheimer's disease. Alzheimer's \& dementia: the journal of the Alzheimer's Association. 2006; 2:59-70.

57. Hirai K, Aliev G, Nunomura A, Fujioka H, Russell RL, Atwood CS, Johnson AB, Kress Y, Vinters HV, Tabaton M, Shimohama S, Cash AD, Siedlak SL, Harris PL, Jones PK, Petersen RB, Perry G, Smith MA. Mitochondrial abnormalities in Alzheimer's disease. J Neurosci. 2001; 21:3017-3023. [PubMed: 11312286]

58. Wang X, Su B, Lee HG, Li X, Perry G, Smith MA, Zhu X. Impaired balance of mitochondrial fission and fusion in Alzheimer's disease. J Neurosci. 2009; 29:9090-9103. [PubMed: 19605646]

59. Manczak M, Reddy PH. Abnormal interaction between the mitochondrial fission protein Drp1 and hyperphosphorylated tau in Alzheimer's disease neurons: implications for mitochondrial dysfunction and neuronal damage. Hum Mol Genet. 2012; 21:2538-2547. [PubMed: 22367970]

60. Manczak M, Calkins MJ, Reddy PH. Impaired mitochondrial dynamics and abnormal interaction of amyloid beta with mitochondrial protein Drp1 in neurons from patients with Alzheimer's disease: implications for neuronal damage. Hum Mol Genet. 2011; 20:2495-2509. [PubMed: 21459773]

61. Cho DH, Nakamura T, Fang J, Cieplak P, Godzik A, Gu Z, Lipton SA. S-nitrosylation of Drp1 mediates beta-amyloid-related mitochondrial fission and neuronal injury. Science. 2009; 324:102105. [PubMed: 19342591]

62. Chen H, Chan DC. Mitochondrial dynamics--fusion, fission, movement, and mitophagy--in neurodegenerative diseases. Hum Mol Genet. 2009; 18:R169-176. [PubMed: 19808793]

63. Nakamura T, Cieplak P, Cho DH, Godzik A, Lipton SA. S-nitrosylation of Drp1 links excessive mitochondrial fission to neuronal injury in neurodegeneration. Mitochondrion. 2010; 10:573-578. [PubMed: 20447471]

64. Bossy B, Petrilli A, Klinglmayr E, Chen J, Lutz-Meindl U, Knott AB, Masliah E, Schwarzenbacher R, Bossy-Wetzel E. S-Nitrosylation of DRP1 does not affect enzymatic activity and is not specific to Alzheimer's disease. J Alzheimers Dis. 2010; 20(Suppl 2):S513-526. [PubMed: 20463395]

65. Wang S, Song J, Tan M, Albers KM, Jia J. Mitochondrial fission proteins in peripheral blood lymphocytes are potential biomarkers for Alzheimer's disease. European journal of neurology: the official journal of the European Federation of Neurological Societies. 2012; 19:1015-1022.

66. Choo YS, Johnson GVW, MacDonald M, Detloff PJ, Lesort M. Mutant huntingtin directly increases susceptibility of mitochondria to the calcium-induced permeability transition and cytochrome c release. Human Molecular Genetics. 2004; 13:1407-1420. [PubMed: 15163634]

67. Petrasch-Parwez E, Nguyen H-P, Löbbecke-Schumacher M, Habbes H-W, Wieczorek S, Riess O, Andres K-H, Dermietzel R, Von Hörsten S. Cellular and subcellular localization of Huntington aggregates in the brain of a rat transgenic for Huntington disease. The Journal of Comparative Neurology. 2007; 501:716-730. [PubMed: 17299753] 
68. Costa V, Giacomello M, Hudec R, Lopreiato R, Ermak G, Lim D, Malorni W, Davies KJ, Carafoli E, Scorrano L. Mitochondrial fission and cristae disruption increase the response of cell models of Huntington's disease to apoptotic stimuli. EMBO molecular medicine. 2010; 2:490-503. [PubMed: 21069748]

69. Kim J, Moody JP, Edgerly CK, Bordiuk OL, Cormier K, Smith K, Beal MF, Ferrante RJ. Mitochondrial loss, dysfunction and altered dynamics in Huntington's disease. Human Molecular Genetics. 2010; 19:3919-3935. [PubMed: 20660112]

70. Shirendeb U, Reddy AP, Manczak M, Calkins MJ, Mao P, Tagle DA, Reddy PH. Abnormal mitochondrial dynamics, mitochondrial loss and mutant huntingtin oligomers in Huntington's disease: implications for selective neuronal damage. Hum Mol Genet. 2011; 20:1438-1455. [PubMed: 21257639]

71. Song W, Chen J, Petrilli A, Liot G, Klinglmayr E, Zhou Y, Poquiz P, Tjong J, Pouladi MA, Hayden MR, Masliah E, Ellisman M, Rouiller I, Schwarzenbacher R, Bossy B, Perkins G, Bossy-Wetzel E. Mutant huntingtin binds the mitochondrial fission GTPase dynamin-related protein-1 and increases its enzymatic activity. Nat Med. 2011; 17:377-382. [PubMed: 21336284]

72. Wang H, Lim PJ, Karbowski M, Monteiro MJ. Effects of overexpression of huntingtin proteins on mitochondrial integrity. Hum Mol Genet. 2009; 18:737-752. [PubMed: 19039036]

73. Squitieri F, Falleni A, Cannella M, Orobello S, Fulceri F, Lenzi P, Fornai F. Abnormal morphology of peripheral cell tissues from patients with Huntington disease. J Neural Transm. 2010; 117:7783. [PubMed: 19834779]

74. Zorzano A, Liesa M, Palacin M. Role of mitochondrial dynamics proteins in the pathophysiology of obesity and type 2 diabetes. Int J Biochem Cell Biol. 2009; 41:1846-1854. [PubMed: 19703653]

75. Anello M, Lupi R, Spampinato D, Piro S, Masini M, Boggi U, Del Prato S, Rabuazzo AM, Purrello F, Marchetti P. Functional and morphological alterations of mitochondria in pancreatic beta cells from type 2 diabetic patients. Diabetologia. 2005; 48:282-289. [PubMed: 15654602]

76. Bindokas VP, Kuznetsov A, Sreenan S, Polonsky KS, Roe MW, Philipson LH. Visualizing superoxide production in normal and diabetic rat islets of Langerhans. J Biol Chem. 2003; 278:9796-9801. [PubMed: 12514170]

77. Men X, Wang H, Li M, Cai H, Xu S, Zhang W, Xu Y, Ye L, Yang W, Wollheim CB, Lou J. Dynamin-related protein 1 mediates high glucose induced pancreatic beta cell apoptosis. Int J Biochem Cell Biol. 2009; 41:879-890. [PubMed: 18805504]

78. Twig G, Elorza A, Molina AJ, Mohamed H, Wikstrom JD, Walzer G, Stiles L, Haigh SE, Katz S, Las G, Alroy J, Wu M, Py BF, Yuan J, Deeney JT, Corkey BE, Shirihai OS. Fission and selective fusion govern mitochondrial segregation and elimination by autophagy. EMBO J. 2008; 27:433446. [PubMed: 18200046]

79. Park KS, Wiederkehr A, Kirkpatrick C, Mattenberger Y, Martinou JC, Marchetti P, Demaurex N, Wollheim CB. Selective actions of mitochondrial fission/fusion genes on metabolism-secretion coupling in insulin-releasing cells. J Biol Chem. 2008; 283:33347-33356. [PubMed: 18832378]

80. Molina AJ, Wikstrom JD, Stiles L, Las G, Mohamed H, Elorza A, Walzer G, Twig G, Katz S, Corkey BE, Shirihai OS. Mitochondrial networking protects beta-cells from nutrient-induced apoptosis. Diabetes. 2009; 58:2303-2315. [PubMed: 19581419]

81. Zhang Z, Wakabayashi N, Wakabayashi J, Tamura Y, Song WJ, Sereda S, Clerc P, Polster BM, Aja SM, Pletnikov MV, Kensler TW, Shirihai OS, Iijima M, Hussain MA, Sesaki H. The dynaminrelated GTPase Opa1 is required for glucose-stimulated ATP production in pancreatic beta cells. Mol Biol Cell. 2011; 22:2235-2245. [PubMed: 21551073]

82. Jheng HF, Tsai PJ, Guo SM, Kuo LH, Chang CS, Su IJ, Chang CR, Tsai YS. Mitochondrial fission contributes to mitochondrial dysfunction and insulin resistance in skeletal muscle. Mol Cell Biol. 2012; 32:309-319. [PubMed: 22083962]

83. Parra V, Verdejo HE, Iglewski M, Campo AD, Troncoso R, Jones D, Zhu Y, Kuzmicic J, Pennanen C, Lopez-Crisosto C, Jana F, Ferreira J, Noguera E, Chiong M, Bernlohr DA, Klip A, Hill JA, Rothermel BA, Abel ED, Zorzano A, Lavandero S. Insulin stimulates mitochondrial fusion and function in cardiomyocytes via the Akt-mTOR-NFkappaB-Opa-1 signaling pathway. Diabetes. 2013 
84. Holmgren D, Wåhlander H, Eriksson BO, Oldfors A, Holme E, Tulinius M. Cardiomyopathy in children with mitochondrial disease: Clinical course and cardiological findings. European Heart Journal. 2003; 24:280-288. [PubMed: 12590906]

85. Chen Y, Liu Y, Dorn GW 2nd. Mitochondrial fusion is essential for organelle function and cardiac homeostasis. Circ Res. 2011; 109:1327-1331. [PubMed: 22052916]

86. Papanicolaou KN, Kikuchi R, Ngoh GA, Coughlan KA, Dominguez I, Stanley WC, Walsh K. Mitofusins 1 and 2 are essential for postnatal metabolic remodeling in heart. Circ Res. 2012; 111:1012-1026. [PubMed: 22904094]

87. Chen L, Liu T, Tran A, Lu X, Tomilov AA, Davies V, Cortopassi G, Chiamvimonvat N, Bers DM, Votruba M, Knowlton AA. OPA1 mutation and late-onset cardiomyopathy: mitochondrial dysfunction and mtDNA instability. Journal of the American Heart Association. 2012; 1:e003012. [PubMed: 23316298]

88. Davies VJ, Powell KA, White KE, Yip W, Hogan V, Hollins AJ, Davies JR, Piechota M, Brownstein DG, Moat SJ, Nichols PP, Wride MA, Boulton ME, Votruba M. A missense mutation in the murine Opa3 gene models human Costeff syndrome. Brain. 2008; 131:368-380. [PubMed: 18222992]

89. Votruba M, Moore AT, Bhattacharya SS. Clinical features, molecular genetics, and pathophysiology of dominant optic atrophy. J Med Genet. 1998; 35:793-800. [PubMed: 9783700]

90. Chen H, Vermulst M, Wang YE, Chomyn A, Prolla TA, McCaffery JM, Chan DC. Mitochondrial fusion is required for mtDNA stability in skeletal muscle and tolerance of mtDNA mutations. Cell. 2010; 141:280-289. [PubMed: 20403324]

91. Vielhaber S, Debska-Vielhaber G, Peeva V, Schoeler S, Kudin AP, Minin I, Schreiber S, Dengler R, Kollewe K, Zuschratter W, Kornblum C, Zsurka G, Kunz WS. Mitofusin 2 mutations affect mitochondrial function by mitochondrial DNA depletion. Acta neuropathologica. 2013; 125:245256. [PubMed: 22926664]

92. Sanders LH, Laganiere J, Cooper O, Mak SK, Vu BJ, Huang YA, Paschon DE, Vangipuram M, Sundararajan R, Urnov FD, Langston JW, Gregory PD, Zhang HS, Greenamyre JT, Isacson O, Schule B. LRRK2 mutations cause mitochondrial DNA damage in iPSC-derived neural cells from Parkinson's disease patients: Reversal by gene correction. Neurobiol Dis. 2013; 62c:381-386.

93. Phillips NR, Simpkins JW, Roby RK. Mitochondrial DNA deletions in Alzheimer's brains: A review. Alzheimer's \& dementia: the journal of the Alzheimer's Association. 2013

94. Corral-Debrinski M, Horton T, Lott MT, Shoffner JM, McKee AC, Beal MF, Graham BH, Wallace DC. Marked changes in mitochondrial DNA deletion levels in Alzheimer brains. Genomics. 1994; 23:471-476. [PubMed: 7835898]

95. Jendrach M, Mai S, Pohl S, Voth M, Bereiter-Hahn J. Short- and long-term alterations of mitochondrial morphology, dynamics and mtDNA after transient oxidative stress. Mitochondrion. 2008; 8:293-304. [PubMed: 18602028]

96. Cereghetti GM, Stangherlin A, Martins de Brito O, Chang CR, Blackstone C, Bernardi P, Scorrano L. Dephosphorylation by calcineurin regulates translocation of Drp1 to mitochondria. Proc Natl Acad Sci U S A. 2008; 105:15803-15808. [PubMed: 18838687]

97. Yu T, Robotham JL, Yoon Y. Increased production of reactive oxygen species in hyperglycemic conditions requires dynamic change of mitochondrial morphology. Proc Natl Acad Sci U S A. 2006; 103:2653-2658. [PubMed: 16477035]

98. Frank S, Gaume B, Bergmann-Leitner ES, Leitner WW, Robert EG, Catez F, Smith CL, Youle RJ. The role of dynamin-related protein 1 , a mediator of mitochondrial fission, in apoptosis. Dev Cell. 2001; 1:515-525. [PubMed: 11703942]

99. Lee YJ, Jeong SY, Karbowski M, Smith CL, Youle RJ. Roles of the mammalian mitochondrial fission and fusion mediators Fis1, Drp1, and Opa1 in apoptosis. Mol Biol Cell. 2004; 15:50015011. [PubMed: 15356267]

100. Brooks C, Dong Z. Regulation of mitochondrial morphological dynamics during apoptosis by Bcl-2 family proteins: a key in Bak? Cell Cycle. 2007; 6:3043-3047. [PubMed: 18073534]

101. Soriano ME, Scorrano L. The interplay between BCL-2 family proteins and mitochondrial morphology in the regulation of apoptosis. Adv Exp Med Biol. 2010; 687:97-114. [PubMed: 20919640] 
102. Landes T, Emorine LJ, Courilleau D, Rojo M, Belenguer P, Arnaune-Pelloquin L. The BH3-only Bnip3 binds to the dynamin Opa1 to promote mitochondrial fragmentation and apoptosis by distinct mechanisms. EMBO Rep. 2010; 11:459-465. [PubMed: 20436456]

103. Karbowski M, Arnoult D, Chen H, Chan DC, Smith CL, Youle RJ. Quantitation of mitochondrial dynamics by photolabeling of individual organelles shows that mitochondrial fusion is blocked during the Bax activation phase of apoptosis. J Cell Biol. 2004; 164:493-499. [PubMed: 14769861]

104. Guo X, Chen KH, Guo Y, Liao H, Tang J, Xiao RP. Mitofusin 2 triggers vascular smooth muscle cell apoptosis via mitochondrial death pathway. Circ Res. 2007; 101:1113-1122. [PubMed: 17901359]

105. Piquereau J, Caffin F, Novotova M, Prola A, Garnier A, Mateo P, Fortin D, Huynh LH, Nicolas V, Alavi MV, Brenner C, Ventura-Clapier R, Veksler V, Joubert F. Down-regulation of OPA1 alters mouse mitochondrial morphology, PTP function, and cardiac adaptation to pressure overload. Cardiovascular Research. 2012; 94:408-417. [PubMed: 22406748]

106. Chen Y, Liu Y, Dorn GW. Mitochondrial Fusion is Essential for Organelle Function and Cardiac Homeostasis/Novelty and Significance. Circulation Research. 2011; 109:1327-1331. [PubMed: 22052916]

107. Williams PA, Morgan JE, Votruba M. Opa1 deficiency in a mouse model of dominant optic atrophy leads to retinal ganglion cell dendropathy. Brain. 2010; 133:2942-2951. [PubMed: 20817698]

108. Amiott EA, Cohen MM, Saint-Georges Y, Weissman AM, Shaw JM. A mutation associated with CMT2A neuropathy causes defects in Fzo1 GTP hydrolysis, ubiquitylation, and protein turnover. Mol Biol Cell. 2009; 20:5026-5035. [PubMed: 19812251] 
Table I

Genetic Abnormalities Associate with Mitochondrial Dynamic Genes

\begin{tabular}{|c|c|c|c|}
\hline Abnormalities & Changes in Mitochondrial dynamic genes & Mitochondria changes \\
\hline CMT2A & MFN2 mutations & Fragmented mitochondria \\
\hline ADOA & OPA1/OPA3 mutations & Fragmented mitochondria \\
\hline ADOAC & Opa3 mutations & Fragmented mitochondria \\
\hline Parkinson's disease & $\begin{array}{c}\text { Parkin/PINK1 mutations; Decreased OPA1, MFN2; } \\
\text { Increased Drp1 }\end{array}$ & Fragmented mitochondria \\
\hline Alzheimer's diseases & $\begin{array}{c}\text { Decreased OPA1, MFN2; Increased Fis1; Decreased } \\
\text { total Drp1 but increased mitochondrial Drp1 }\end{array}$ & Fragmented mitochondria \\
\hline Huntington's diseases & Increased Drp1 and Fis1 & $\begin{array}{c}\text { Fragmented mitochondria in neuron cell, but } \\
\text { giant mitochondria in muscle and skin cell }\end{array}$ & (68-71) \\
\hline Diabetes & Decreased MFN2, OPA1; Increased Drp1, Fis1 & Shorter, swollen mitochondria \\
\hline Cardiomyopathy & Loss of MFN2 & Fragmented mitochondria \\
\hline
\end{tabular}

